\title{
Pattern of Morbidities in Under Five Children and Health Seeking Behaviour of their Parents
}

\author{
Anne RA ${ }^{1}$, Akhter $N^{2}$, Shapla $\mathrm{NR}^{3}$, Jesmin $\mathrm{E}^{4}$, Begum $\mathrm{N}^{5}$
}

\begin{abstract}
Introduction: All children, no matter where they born, deserve a healthy start in life. But harsh reality is that, in year 2012, 6.6 million children died in Bangladesh before their fifth birthday. The children constitute a large proportion of the total population of Bangladesh. They are 15 million, the vulnerable or special risk group; deserve exceptional health care as the child mortality and morbidity risks are much higher than their later life. Child morbidity is determined by several complex and inter-related factors in Bangladesh, specially in rural area.
\end{abstract}

Objectives: The objective of this study was to find out the pattern of morbidity of under five children, health seeking behaviour of their parents and the socio-demographic factors affecting those under five children's morbidity.

Materials and Methods: This descriptive type of cross sectional study was carried out at Madhupur Thana under a rural area of Tangail District during January 2012 to June 2012 to find out the pattern of morbidities of under five children and health seeking behaviour of their parents. Total 170 mothers were selected purposively to carry out this study.

Results: Among the cases of morbidities, $611(100 \%)$ sufferings of under five children were recorded from 170 respondents. The highest frequency $(133,21.76 \%)$ of sufferings of under five children were from cold, almost the similar number $(132,21.6 \%)$ of sufferings were from fever and $116(16.69 \%)$ sufferings were from diarrhoea. In this study, health care seeking behaviour for their children were found towards blessings from religious person (Jarphuk/Tabiz-11.77\%), spiritual healer (Kobiraj-8.82\%), herbal(7.06\%), village doctor(20\%) drug seller $(17.06 \%)$, homeopath $(12.94 \%)$, paramedic $(4.71 \%)$, MBBS doctors $(9.41 \%)$ and $8.23 \%$ did not take any treatment. Monthly income level of $51.8 \%$ respondents were from Taka $5000 /$ - to Taka 10,000/-. On the other hand, only 07 respondents had highest level income of Taka $20,000 /$ - to Taka 30,000/-. The mean income of the mother of under five children was Tk 10,064/- (SD= \pm 5709.06).

This study revealed that 14 respondents out of 170 did not take any treatment for their under five children. Out of these 14 respondents, 02(14.28\%) even did not know the existence of treatment for the morbidity of their under five children. Again, $05(35.71 \%)$ respondents had the belief that their children would get cured without any medicine, 04 $(28.57 \%)$ respondents had no health care centre nearby and $03(21.42 \%)$ respondents were unable to bear the treatment cost.

Conclusion: Education and awareness of the parents about child health care are important components to reconsider for developing new strategy for improving existing situation of health seeking behaviour of parents for their under-5 children.

Key-words: Child mortality, child morbidity, under five children, health seeking behavior (HSB).

\section{Introduction}

Every year, over 8.1 million children aged upto 5 years, die globally and about $40 \%$ of these deaths take place within the first 23 days of life that is in the neonatal period ${ }^{1}$. WHO and UNICEF jointly address five leading causes of childhood deaths in the world.

1. Lt Col Rownok Azad Anne, MBBS, MPH (RCH), Director Medical, Sector Head Quarters, BGB, Dhaka; 2. Lt Col Neelima Akhter, MBBS, MPH (RCH), CO-Family Wing, CMH, Dhaka; 3. Lt Col Nahid Reaz Shapla, MBBS, MCPS, FCPS(Gynae \& Obs), Gynaecologist, BGB Hospital, Peelkhana, Dhaka; 4. Lt Col Eva Jesmin, MBBS, FCPS(Paediatrics), BGB Hospital, Peelkhana, Dhaka; 5. Lt Col Nazma Begum, MBBS, $\mathrm{MPH}(\mathrm{RCH}), \mathrm{CMH}$, Dhaka. 
These five diseases are; pneumonia, diarrhoea, measles, malaria and malnutrition. These are associated with almost $70 \%$ of all childhood deaths in developing countries ${ }^{2}$. The majority of the children in the world lives in developing countries like Bangladesh and spend their childhood with hundreds of problems, specially health related one. Among 154 million population of Bangladesh, 15 million $^{3}(10 \%$ of total population) are below 05 years of age, who falls under this group.

The children of Bangladesh are more victimized than those in other parts of the world. Because of poverty, neither the mothers have access to medical facilities available in the area nor do their children. Moreover, the nutritional status of mothers and children are very poor, about a quarter of infants in Bangladesh have low birth weights. According to UNICEF- Key Statistics on Child Survival in Bangladesh, the infant mortality rate is about 37 deaths per 1000 live births and that of under five children is 52 per 1000. Though the infant and child mortality rate has decreased but it is still a burning problem in Bangladesh. Despite our recent decline in infant and child mortality, this level is one of the highest in the world. It is also noted that maternal mortality and morbidity is also at higher level in Bangladesh ${ }^{4}$.

In our society cultural beliefs, attitudes and superstition greatly influence the pathogenesis of disease and also HSB. Majority of the parents are not aware about the illness of their infants due to lack of knowledge basically due to poor educational background $^{5}$. Data of different authors in Bangladesh have been reviewed to assess the magnitude of morbidities \& HSB of under five children. Various studies show that common disease of under five children are gastroenteritis, pneumonia, diarrhoea, skin infection, helminthiasis, abdominal pain, dental problem \& chronic supporative otitis media.Another study in Bangladesh on HSB of the parents of under five children found that majority sought treatment from Homeopaths and nonqualified allopaths. Only a few of them received modern allopathic treatments ${ }^{5,6}$. This study was carried out to focus some clue for future planning \& management of under five morbid children and evaluation of the outcome of existing programme and come up with a suggestion for necessary modifications.

\section{Materials and Methods}

This study was a descriptive type of cross sectional study and respondents were selected purposively from the mothers having under five children in a rural community in Madhupur thana of Tangail district during January to June 2012. Apart from morbidity pattern and HSB of the parents of under five children, information on socio-demographic factors that affect the morbidity pattern were obtained.

A total of 170 mothers were selected purposively. Semi structured questionnaire was prepared containing the socio-demographic variable related to morbidity and also the variables related to HSB. All rural mothers who have children of both sex (male and female) of less than five years of age were included in this study. The exclusion criteria for this study were children of age more than 5 years. Seriously sick children, physically disabled and psychiatric disordered mothers having under five children were excluded from the study.

Data processing and analyses were done using SPSS ( Statistical Package for Social Sciences) version 17.0 Data were analyzed according to objectives of the study, The test statistics used to analyze the data were descriptive statistics and $\mathrm{Chi}$ square(X2). Level of significance was set at $<0.05$.

\section{Results}

Table-I showed the different diseases suffered by the children during last April, May and June of year 2012. The children mostly suffered from cold, fever and diarrhoea.

Table-I: Name of the diseases suffered by the children during last three months $(n=611)$.

\begin{tabular}{|l|c|c|}
\hline Name of Diseases & Number of Responses & Percentage \\
\hline Common Cold & 133 & 21.76 \\
\hline Fever & 132 & 21.6 \\
\hline Diarrhoea & 102 & 16.69 \\
\hline Skin disease/Scabies & 109 & 17.83 \\
\hline Loss of appetite & 67 & 10.96 \\
\hline Pneumonia & 24 & 3.92 \\
\hline Dysentery & 37 & 6.05 \\
\hline Others & 7 & 1.14 \\
\hline Total & 611 & 100 \\
\hline
\end{tabular}


Table-II showed the distribution of health care seeking behaviour of mothers for their under five children. The highest responses (20\%) were towards village doctors, the second highest responses were towards Drug Seller (17.059\%), 3rd highest responses were towards Jharphuk/Tabij (11.765\%). Only $9.412 \%$ went to MBBS Doctors for treatment of their under five children. Surprisingly, $8.235 \%$ of total respondents did not take any treatment.

Table-II: Distribution of the respondents by health care seeking behaviour for their children $(n=170)$.

\begin{tabular}{|l|c|c|}
\hline Health Seeking Behaviour & $\begin{array}{c}\text { Frequency of } \\
\text { Responses }\end{array}$ & $\begin{array}{c}\text { Percentage } \\
\text { (\%) }\end{array}$ \\
\hline Jharphuk/Tabij & 20 & 11.765 \\
\hline Kobiraj (Spiritual Healer) & 15 & 8.824 \\
\hline Herbal medicine & 12 & 7.059 \\
\hline Village doctor & 34 & 20 \\
\hline Drug seller/self medication & 29 & 17.059 \\
\hline Homeopath & 22 & 12.941 \\
\hline Paramedic & 08 & 4.705 \\
\hline MBBS Doctors & 16 & 9.412 \\
\hline Did Not Take Any Treatment & 14 & 8.235 \\
\hline Total & $\mathbf{1 7 0}$ & $\mathbf{1 0 0 . 0 0 0}$ \\
\hline
\end{tabular}

Table-III showed the distribution of the respondents by their monthly income. More than half of the respondents 88(51.8\%) had Tk 5001- Tk 10000 income level. Highest income level was Tk. 20001-Tk. 30000 , only $7(4.1 \%)$ respondents had the highest level of income. The mean income was Tk $10064(S D= \pm 5709.06)$.

Table-III: Distribution of the respondents by monthly income $(n=170)$.

\begin{tabular}{|l|c|c|}
\hline Monthly income in TK & Frequency & Percentage \\
\hline$\leq 5000$ & 32 & 18.8 \\
\hline $5001-10000$ & 88 & 51.8 \\
\hline $10001-20000$ & 43 & 25.3 \\
\hline $20000+$ & 7 & 4.1 \\
\hline Total & $\mathbf{1 7 0}$ & $\mathbf{1 0 0 . 0}$ \\
\hline
\end{tabular}

Out of the 14 respondents, $35.71 \%$ believed that their child will get cured without medicine, $28.57 \%$ reported that there were no health care centre nearby them, $21.43 \%$ were unable to bear treatment cost, and $14.29 \%$ did not know anything about the treatment (Table-IV).
Table-IV: Reason for not taking treatment $(n=14)$.

\begin{tabular}{|l|c|c|}
\hline Reason of not taking treatment & Frequency & Percentage \\
\hline Don't Know & 2 & 14.29 \\
\hline No health centre near by & 4 & 28.57 \\
\hline Will get cured without medicine & 5 & 35.71 \\
\hline Unable to bear treatment cost & 3 & 21.43 \\
\hline Total & $\mathbf{1 4}$ & $\mathbf{1 0 0 . 0 0}$ \\
\hline
\end{tabular}

Table-V showed the relationship between the respondents' educational status who sought health care for their under five children and health seeking behaviors. Out of 170 respondents 18 were totally illiterate, 152 respondents had two different levels of education which were considered in the study. Out of 118 respondents whose education is above class five, 67 respondents showed healthy HSB for their under five children; than the respondents having lower educational level. Out of 34 respondents, having lower educational background, 22 showed unhealthy HSB (seeking treatment from spiritual healer, village quacks other than medical practitioners). There were significant relationship found between respondents' educational level and HSB for their under five children.

Table-V: Association between the respondents' educational level and HSB for their under five children ( $n=152)$.

\begin{tabular}{|l|c|c|c|c|c|c|c|}
\hline \multirow{2}{*}{$\begin{array}{c}\text { Educational } \\
\text { Level }\end{array}$} & \multicolumn{3}{|c|}{ Health seeking behaviours } & Total & $X^{2}$ & P value \\
\cline { 2 - 8 } & $\begin{array}{c}\text { Healthy } \\
\text { Behaviours } \\
\text { (MBBS Doctors) }\end{array}$ & $\begin{array}{c}\text { Unhealthy } \\
\text { Behaviours } \\
\text { ( Quacks) }\end{array}$ & & & \\
\hline & $\mathrm{n}$ & $\%$ & $\mathrm{n}$ & $\%$ & & & \\
\hline Upto Class-V & 12 & 15.2 & 22 & 30.1 & 34 & 4.88 & 0.02 \\
\hline Above Class-V & 67 & 84.8 & 51 & 69.9 & 118 & & \\
\hline Total & $\mathbf{7 9}$ & & $\mathbf{7 3}$ & & $\mathbf{1 5 2}$ & & \\
\hline
\end{tabular}

Table-VI showed the relationship between age of the mothers who sought health care for their under five children and health seeking behaviors. In this study, 18 mothers were less than 15 years and they were not considered (They were too young to become a mother). Besides these 18 respondents, lower the age group of mother showed healthier HSB than the respondents of higher age group. There was significant relationship between age of the mothers and HSB for their under five children. As the age of the mother increases, their pattern of HSB for their under five children also declines. 
Table-VI: Relation of mothers' age and health seeking behaviour $(n=152)$.

\begin{tabular}{|c|c|c|c|c|c|c|c|}
\hline \multirow{3}{*}{$\begin{array}{l}\text { Age in } \\
\text { years }\end{array}$} & \multicolumn{4}{|c|}{ Health seeking behaviours } & \multirow[t]{2}{*}{ Total } & \multirow[t]{2}{*}{$x^{2}$} & \multirow[t]{2}{*}{$P$ value } \\
\hline & \multicolumn{2}{|c|}{$\begin{array}{c}\text { Healthy } \\
\text { Behaviours } \\
\text { (MBBS Doctors) }\end{array}$} & \multicolumn{2}{|c|}{$\begin{array}{l}\text { Unhealthy } \\
\text { Behaviours } \\
\text { ( Quacks) }\end{array}$} & & & \\
\hline & $\mathrm{n}$ & $\%$ & $n$ & $\%$ & & & \\
\hline $15-30$ & 50 & 54.9 & 48 & 78.7 & 98 & 4.56 & 0.033 \\
\hline $31-45$ & 41 & 45.1 & 13 & 21.3 & 54 & & \\
\hline Total & 91 & 59.87 & 61 & 40.13 & 152 & & \\
\hline
\end{tabular}

\section{Discussion}

The study was carried out to find out the morbidity pattern and HSB of parents of under five children. A total 170 mothers were selected purposively. The under five children in this study suffered from fever $(21.6 \%)$, cold $(21.7 \%)$, diarrhoea $(16.69 \%)$ pneumonia $(3.92 \%)$. Another similar study on the national data on under five children showed that morbidities were due to fever $(11 \%)$, diarrhoea $(17 \%)$ and pneumonia (9\%). In both studies, it was found that the morbidities by diarrohea are almost similar, $16.69 \%$ in this study and $17 \%$ in the statistics of other similar study ${ }^{7}$.

In the present study, distribution of health seeking behaviours of the respondents for their under five children were as follow; towards MBBS doctor it was $9.412 \%$, towards drug seller $17.059 \%$ and towards village doctor $20.00 \%$ and good number towards Jarphuk and Tabij (11.765\%), Homeopathic $(12.941 \%)$, Kabiraj(8.824\%) and again some respondents sought treatment advice from paramedics $(4.705 \%)$. Similar cross sectional study ${ }^{8}$ was conducted in Tamil Nadu India to find out the morbidity pattern, health care utilization and per capita health expenditure in rural population. The study at Tamil Nadu revealed that $79 \%$ mothers of under five children opted for allopathic treatment. Present study identified the need to improve the access of mother to MBBS (trained allopathic) doctors of under five children which is lower than that of India (Tamil Nadu) ${ }^{8}$. In the present study it was found that, the majority of the respondents had their level of income at Tk. 5000/- to Tk. 10.000/which is $51.8 \%$ of total respondents. It reflects the poverty and wealth status of the respondents, which is the major determinant in the health seeking behavior of the under five children. A cross sectional study was carried out in rural villages of Bangladesh in three different divisions ${ }^{9}$ where 128 married women were chosen purposively to determine the socioeconomic factors affecting under five children's health seeking behavior. It was found in that study, that within rural areas of Bangladesh, overall poverty level is always high, and wealth status remained as an important factor in the health seeking behavior. Findings of present study is consistent with the findings of this study where the socio economical status of the respondents has direct bearing on the pattern of morbidities and health seeking behaviour of under five children.

The present study showed the "Reasons of not taking treatment" by the mother of under five children. It can be compared with a community based comparative cross sectional study which was conducted in Derra district of Ethiopia ${ }^{10}$ in the year 2007. This study revealed that the Health Care Centres are not available near to the residence of mother of under five children (27\%). Present study showed that the mother of under five children does not have health care centre near by their residences are $28 \%$. The countries in both studies are from the developing world or $3 \mathrm{rd}$ world, where the health care centres are scarce in the rural area or grass root level. In the present study it was found that the age and educational status of child's mother has direct association with under five children's morbidity. A similar study carried out on parental HSB for childhood illness in Vietnam ${ }^{11}$, showed relation between the perception of illness with the age and education of under five child's mother. As the age of the mother increases, their pattern of HSB for their under five children declines. On the contrary, the study shows that some level of education of the respondents results into a healthy HSB (Present study is consistent with the findings of the study carried out at Vietnam).

\section{Conclusion}

Knowledge on causes of death among under five children is very important because it is pertinent to policies and programmes. Patterns and trends in causes of under five mortality, helps the decision makers to assess programmatic needs, prioritize interventions and monitor progress. Present study highlights the requirement to raise the community awareness regarding under five child morbidity, its prevention and importance of receiving health care from physicians of health centres. Information 
related to morbidity and health seeking pattern identified in this study may focus some clues for future planning and management of under five morbid child in Bangladesh.

\section{References}

1. Ahamd OB, Lopez AD, Inoue M. The decline in child mortality: a reappraisal. Bull world health Organization 2000; 78:1175-91.

2. World Health Organization- The world Health report 1997: Conquering suffering enriching humanity; report of the Director General, Geneva: World Health Organization,1997.

3. Neonatal and Child Health Profile, Department of Maternal, Newborn, Child and Adolescent Health (MCA/WHO).http://www.who.int/maternal_child adolescent/epidemiology/profiles/neonatal_child/bgd.pdf.

4. UNICEF - Key Statistics on Child Survival in Bangladesh, http://www.unicef.org/ bangladesh/ Child_Surviva_in_Bangladesh.pdf

5. Yasuko MZ. Disease and Infant Mortality in Children at Bogra Mission Hospital Bangladesh Journal of child health 1983; Vol 7: 79.
6. Chowdhury MS. Pattern of Diseases in Children, Bangladesh Journal of Child Health. 1988; Vol. 1:7.

7. IMCl Newsletter: 2009: MIS-H, DGHS, Dhaka, Bangladesh.

8. Rajaratnam J, Abel R, Duraisamy S et al. Morbidity pattern, health care utilization and per capital health expenditure in rural population of Tamil Naru. Natl-Med-J. India. Nov-Dec 1996; 9(6):259-62.

9. Amin R, Nirali M, Shah Pf. Stan Becker, Socioeconomic factors differentiating maternal and child health-seeking behaviour in rural Bangladesh: A cross-sectional analysis, 2006.

10. Assefa T, Belachew T, Tegegeon A. Mother's Health Care Seeking Beahviour For Childhood Illness in Derra District, Northshoa Zone, Oromia Regional State, Ethiopia.

11. Teerawichitchainan B, James FP. Phillips, Ethnic Differentials in Parental Health Seeking for Childhood Illness in Vietnam,Working paper no.03 2007. 